\title{
Preparation and Hydro-Lipophilic Properties of Selected Novel Chlorinated and Brominated $N$-Arylcinnamamides ${ }^{\dagger}$
}

\author{
Tomas Strharsky 1,*, Timotej Jankech ${ }^{2}$, Jiri Kos ${ }^{1}$, Kristina Maricakova ${ }^{3}$, Andrea Pramukova ${ }^{3}$, \\ Milan Hutta ${ }^{2}$, Ferdinand Devinsky ${ }^{3}$ and Josef Jampilek ${ }^{1,2}$ \\ 1 Division of Biologically Active Complexes and Molecular Magnets, Regional Centre of Advanced \\ Technologies and Materials, Faculty of Science, Palacky University, Slechtitelu 27, 78371 Olomouc, Czech \\ Republic; jiri.kos@upol.cz (J.K.); josef.jampilek@gmail.com (J.J.) \\ 2 Department of Analytical Chemistry, Faculty of Natural Sciences, Comenius University, Ilkovicova 6, 842 \\ 15 Bratislava, Slovakia; timotej.jankech@gmail.com (T.J.); milan.hutta@uniba.sk (M.H.) \\ 3 Faculty of Pharmacy, Comenius University, Odbojarov 10, 83232 Bratislava, Slovakia; \\ maricakova@centrum.sk (K.M.); andreapramukova@gmail.com (A.P.); devinsky@fpharm.uniba.sk (F.D.) \\ * Correspondence: tomas.strharsky01@upol.cz \\ + Presented at the 23rd International Electronic Conference on Synthetic Organic Chemistry, 15 November-15 \\ December 2019; Available online: https://ecsoc-23.sciforum.net/.
}

Published: 14 November 2019

\begin{abstract}
A series of six di- and tri-halogenated $N$-arylcinnamanilides designed as anti-inflammatory and antimicrobial agents was prepared and characterized. Since it is known that lipophilicity significantly influences the biological activity of compounds, the hydro-lipophilic properties of these di- and tri-substituted $\mathrm{N}$-arylcinnamanilides were investigated in the study. All the discussed derivatives of cinnamic acid were analyzed using the reversed-phase high performance liquid chromatography method to measure lipophilicity. The procedure was performed under isocratic conditions with methanol as an organic modifier in the mobile phase using an end-capped non-polar $C_{18}$ stationary reversed-phase column. In the present study, the correlations between the logarithm of the capacity factor $k$ and $\log P / C \log P$ values calculated in various ways as well as the relationships between the lipophilicity and the chemical structure of the studied compounds are discussed.
\end{abstract}

Keywords: cinnamamides; synthesis; lipophilicity determinations; structure-lipophilicity relationships

\section{Introduction}

One of major prerequisites for pharmacological screening and drug development is the prediction of absorption, e.g., the transport of a molecule through membranes. The drugs most frequently cross biological barriers by passive transport, which strongly depends on lipophilicity. Therefore, hydro-lipophilic properties are one of the most important physical characteristics of biologically active compounds $[1,2]$. The thermodynamic parameter characterized by the partition $(\log P)$ coefficient describes the partitioning of a compound between an aqueous and an organic phases [3]. Classical methods for the determination of these constants are time consuming and not always sufficiently reliable. Therefore, reversed-phase high performance liquid chromatography (RP-HPLC) methods have become popular and widely used for lipophilicity measurement. A general procedure is the measurement of directly accessible retention time under isocratic conditions with varying amounts of an organic modifier in the mobile phase using end-capped non-polar $\mathrm{C}_{18}$ 
stationary RP columns and calculating the capacity factor $k$ [4-9]. $\log k$, calculated from the capacity factor $k$, is used as the lipophilicity index converted to $\log P$ scale [4].

Ring-substituted $\mathrm{N}$-arylcinnamanilides were recently synthesized and tested for their antibacterial, antimycobacterial, and antifungal activity as well as for their activity related to the inhibition of photosynthetic electron transport (PET) in spinach (Spinacia oleracea L.) chloroplasts $[10,11]$. These compounds were designed based on the excellent experience with naphthalenecarboxamides-simple molecules with a number of biological activities, and in fact, ring-substituted (2E)- $N$-aryl-3-phenylprop-2-enamides can be considered as open or radical analogues of described naphthalene-2-carboxanilides [12-17] characterized by high spatial flexibility and solubility, see Figure 1 . Since $N$-phenylcinnamamide skeleton can be considered as a privileged scaffold providing multi-target agents, new anilide halogenated derivatives were prepared. As it was found that the lipophilicity of these significantly biologically effective agents determines their activity $[10,11]$, in this short study, the hydro-lipophilic properties of new di- and tri-substituted $\mathrm{N}$-arylcinnamanilides are investigated.

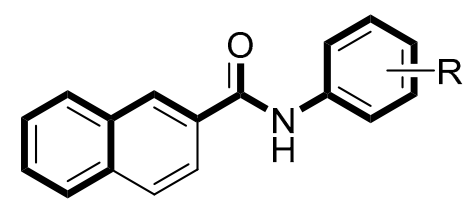

Figure 1. Analogy of (2E)-N-aryl-3-phenylprop-2-enamides with $N$-aryl-naphthalene-2-carboxanilides.

\section{Results and Discussion}

The condensation of cinnamic acid with appropriate substituted anilines using phosphorus trichloride in dry chlorobenzene under microwave conditions gave a series of investigated $\mathrm{N}$-arylcinnamamides 1-7 (see Scheme 1). Unsubstituted derivative $\mathbf{1}$ was published by Pospisilova et al. [10].

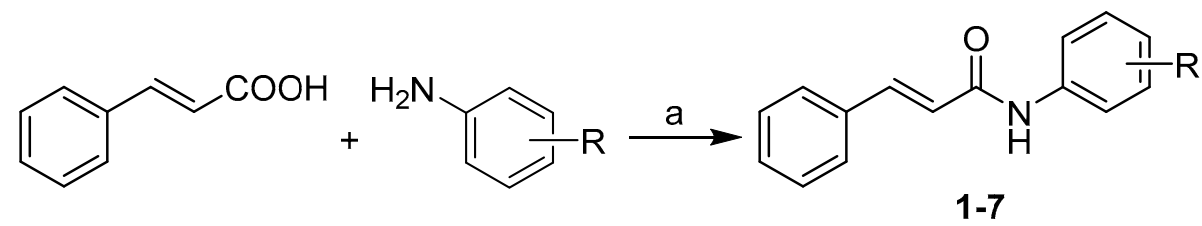

Scheme 1. Synthesis of ring-substituted (2E)-N-aryl-3-phenylprop-2-enamides 1-7. Reagents and conditions: (a) $\mathrm{PCl}_{3}$, chlorobenzene, $\mathrm{MW}, 15 \mathrm{~min}$. [10].

The lipophilicities ( $\log P / C \log P$ data) of all seven anilides were calculated using three commercially available programs: ACD/ChemSketch ver. 2012, ACD/Percepta ver. 2012, and ChemBioDraw Ultra 13.0. In addition, the lipophilicity of the studied compounds was investigated by means of RP-HPLC determination of capacity factors $k$ with a subsequent calculation of $\log k$. The retention times of individual compounds were determined under isocratic conditions with methanol as an organic modifier in the mobile phase using end-capped non-polar C18 stationary RP columns. All the results are shown in Table 1.

$\log P$ values calculated by the ChemBioDraw software for individual anilide positional isomers, i.e., for compounds $4(\mathrm{R}=2,4,5-\mathrm{Cl})$ and $5(\mathrm{R}=3,4,5-\mathrm{Cl})$ as well as $6(\mathrm{R}=3-\mathrm{Cl}-4-\mathrm{Br})$ and 7 $(\mathrm{R}=2-\mathrm{Br}-4-\mathrm{Cl})$, are not distinguished; therefore, these values are listed only in Table 1 without other discussion. The match of experimental and calculated $C \log P$ (ChemBioDraw) values of the substituted compounds is illustrated in Figure 2A; $\log P$ (ACD/Percepta) values versus $\log k$ of the discussed derivatives are plotted in Figure 2B, while the conformity of experimental $\log k$ and calculated $\log P(\mathrm{ACD} /$ ChemSketch) values of the substituted compounds is illustrated in Figure $2 \mathrm{C}$. All calculated lipophilicity values for compounds 1-7 have conformity with experimentally determined $\log k$ (correlation coefficients $r=0.9535,0.9889$, and 0.9872 for $n=7$ ), see Figure 2 . 
Table 1. Structure of ring-substituted $N$-arylcinnamanilides 1-7, calculated lipophilicities (log P/Clog $P$ ), and experimentally determined $\log k$ values of investigated compounds.

\begin{tabular}{ccccccc}
\hline & & & & & \\
\end{tabular}
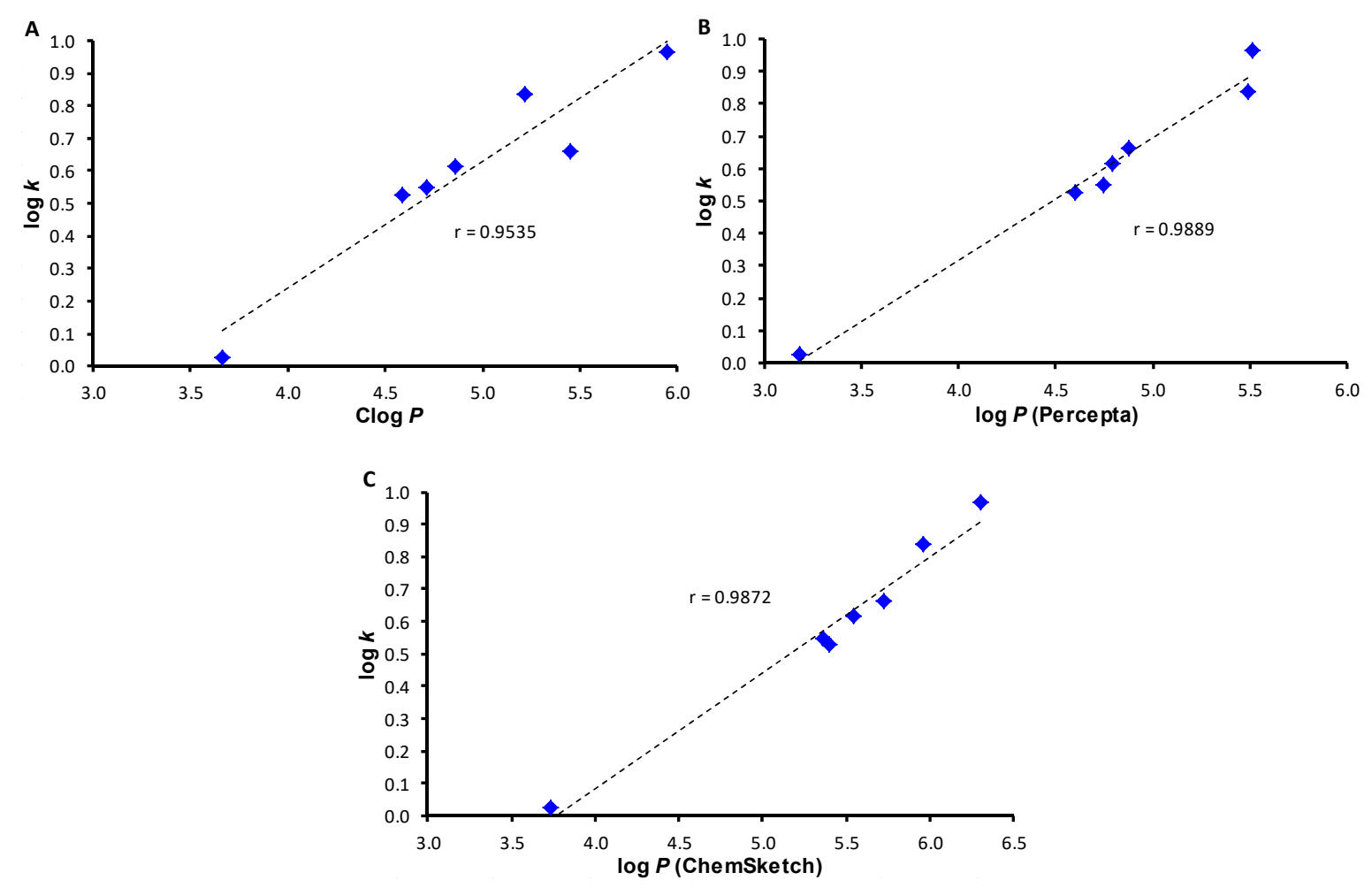

Figure 2. Comparison of experimentally found $\log k$ values with calculated $C \log P$ (ChemBioDraw, (A), $\log P$ (ACD/Percepta, (B), and $\log P$ (ACD/ChemSketch, (C) of N-arylcinnamanilides 1-7.

Although the correlation coefficient is relatively high, several interesting dissimilarities can be observed. All lipophilicity values unambiguously showed that unsubstituted compound 1 showed the lowest lipophilicity, while compound $5(\mathrm{R}=3,4,5-\mathrm{Cl})$ showed the highest lipophilicity. Compound 3 ( $\mathrm{R}=2,4-\mathrm{Br}$ ) demonstrated hydro-lipophilic properties in the middle of lipophilicity values within the investigated series. But ADC/ChemSketch considered compound $7(\mathrm{R}=2-\mathrm{Br}-4-\mathrm{Cl})$ as less lipophilic than compound $2(\mathrm{R}=2,4-\mathrm{Cl})$ contrary to other calculated $\log P / \mathrm{Clog} P$ values as well as the determined $\log k$ data. On the other hand, $C \log P$ values calculated by ChemBioDraw were less for compound $4(\mathrm{R}=2,4,5-\mathrm{Cl})$ and higher for compound $6(\mathrm{R}=3-\mathrm{Cl}-4-\mathrm{Br})$, which was in the opposite trend to the calculated $\log P$ values by both ACD programs and the determined $\log k$ data.

Regarding these observations, it should be noted that the programs cannot always exactly calculate the lipophilicity contribution of substituents in ortho positions, e.g., in this case due to 
spatially close carboxamide linker $[10,12,16,18-20]$ (see compounds $7 / 2$ or $4 / 6$ when evaluated 2-Br-4-Cl (7) was less lipophilic than 2,4-Cl (2) and, to the contrary, disubstituted 3-Cl-4- $\mathrm{Br}(6)$ was more lipophilic than trisubstituted $2,4,5-\mathrm{Cl}(4))$. These facts are caused by intramolecular interactions that can be observed just for ortho substituents/substitutions [10,12,16,18-20,21].

Distributive parameters $\pi$ describe the lipophilicity contribution of individual moieties substituted in some skeleton [22,23]. These $\pi$ parameters characterizing the hydrophobicity of individual substituents were calculated according to the formula $\pi=\log k \mathrm{~s}-\log k \mathrm{u}$, where $\log k \mathrm{~s}$ is the determined capacity factor logarithm of individual substituted compounds and log $k \mathrm{u}$ denotes the determined capacity factor logarithm of unsubstituted compound 1 ; it means $\pi=0$. The $\pi$ values of individual substituted anilide rings $\left(\pi_{\mathrm{Ar}}\right)$ of the discussed compounds are shown in Table 2, where it is possible to see discrepancies between experimental and calculated $\pi$ Ar values (mutual order of values) especially for compounds $3(\mathrm{R}=2,4-\mathrm{Br})$ and $6(\mathrm{R}=3-\mathrm{Cl}-4-\mathrm{Br})$. These observed discrepancies

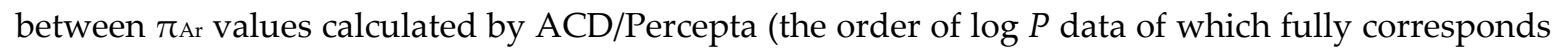
to experimentally determined $\log k$, see Table 1 ) are only lipophilicity contributions without possible interactions of substituents in the ortho position with a carboxamide group within one molecule,

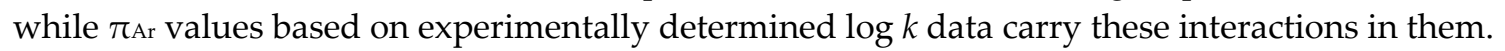

Table 2. Comparison of determined distributive parameters $\pi$ calculated from $\log k$ for each individual substituted anilide ring within the investigated series of $N$-arylcinnamanilides 1-7 and parameters $\pi$ of individual substituted anilide rings predicted by ACD/Percepta.

\begin{tabular}{cccc}
\hline Comp. & $\mathbf{R}$ & $\begin{array}{c}\boldsymbol{\pi}_{\mathrm{Ar}} \\
\text { (Experimental) }\end{array}$ & $\begin{array}{c}\boldsymbol{\pi}_{\mathrm{Ar}} \\
\text { (Percepta) }\end{array}$ \\
\hline $\mathbf{1}$ & $\mathrm{H}$ & 0 & 1.76 \\
$\mathbf{2}$ & $2,4-\mathrm{Cl}$ & 0.50 & 2.82 \\
$\mathbf{3}$ & $2,4-\mathrm{Br}$ & 0.59 & 3.18 \\
$\mathbf{4}$ & $2,4,5-\mathrm{Cl}$ & 0.81 & 3.18 \\
$\mathbf{5}$ & $3,4,5-\mathrm{Cl}$ & 0.94 & 3.22 \\
$\mathbf{6}$ & $3-\mathrm{Cl}-4-\mathrm{Br}$ & 0.63 & 3.14 \\
$\mathbf{7}$ & $2-\mathrm{Br}-4-\mathrm{Cl}$ & 0.52 & 2.85 \\
\hline
\end{tabular}

Nevertheless, based on the results of this preliminary study of several chosen new anilides of cinnamic acid, it can be assumed that $\log P$ values predicted by ACD/Percepta recognized hydro-lipophilic properties in a good agreement with experimentally determined log $k$ values, and thus, this software can be used for these simple chlorinated and brominated derivatives of $\mathrm{N}$-arylcinnamanilides as a useful and mainly fast tool for the subsequent investigation of structure-activity relationships.

Note, based on the previous experience [10,12,16,18-20], it can be supposed that once anilide is substituted by fluorine or trifluoromethyl moieties (still within halogene substituents), only experimentally determined $\log k$ values specify well the lipophilicity of the compounds due to strong intra- and intermolecular interactions of these specific substituents with the rest of pattern molecule or with the second compound or with medium.

\section{Experimental}

\subsection{General}

All reagents were purchased from Merck (Sigma-Aldrich, St. Louis, MO, USA) and Alfa (Alfa-Aesar, Ward Hill, MA, USA). Reactions were performed using a CEM Discover SP microwave reactor (CEM, Matthews, NC, USA). Melting points were determined on an apparatus STA 449 F1 Jupiter (NETZSCH, Selb, Germany) and are uncorrected. Infrared (IR) spectra were recorded on an ATR Zn/Se for a Nicolet ${ }^{\mathrm{TM}}$ iS 5 FT-IR spectrometer (Thermo Fisher Scientific, West Palm Beach, FL, USA). The spectra were obtained by the accumulation of 64 scans with $4 \mathrm{~cm}^{-1}$ resolution in the region of $4000-400 \mathrm{~cm}^{-1}$. All ${ }^{1} \mathrm{H}$ - and ${ }^{13} \mathrm{C}-\mathrm{NMR}$ spectra were recorded on a JEOL JNM-ECA 600II NMR 
spectrometer (600 MHz for ${ }^{1} \mathrm{H}$ and $150 \mathrm{MHz}$ for ${ }^{13} \mathrm{C}$, Jeol, Tokyo, Japan) in dimethyl sulfoxide- $d_{6}$ (DMSO- $\left.d_{6}\right),{ }^{1} \mathrm{H}$ and ${ }^{13} \mathrm{C}$ chemical shifts $(\delta)$ are reported in ppm.

\subsection{Synthesis}

Cinnamic acid $(3.37 \mathrm{mM})$ was suspended at room temperature in dry chlorobenzene $(20 \mathrm{~mL})$ inside a microwave tube, where phosphorus trichloride $(1.7 \mathrm{mM})$ and the corresponding aniline derivative $(3.37 \mathrm{mM})$ were added dropwise. Following this step, a magnetic stirrer was added to the tube and the reaction mixture was transferred to the microwave reactor at $120^{\circ} \mathrm{C}$ for $20 \mathrm{~min}$, where the synthesis at elevated pressure was performed. After the mixture was cooled to $60^{\circ} \mathrm{C}$, the solvent was evaporated in vacuum. A solid residue was washed with $2 \mathrm{M} \mathrm{HCl}$, and a crude product was recrystallized, using $96 \%$ ethanol first, and then using $50 \%$ ethanol. All the studied compounds are presented in Table 1.

Described (2E)-N-phenyl-3-phenylprop-2-enamide (1) was characterized recently by Pospisilova et al. [10].

(2E)-N-(2,4-Dichlorophenyl)-3-phenylprop-2-enamide (2) [24]. Yield 62\%; $\mathrm{Mp} 169.3{ }^{\circ} \mathrm{C}$; IR ( $\left.\mathrm{cm}^{-1}\right)$ : 3264, 3071, 3027, 1654, 1620, 1578, 1524, 1471, 1448, 1380, 1335, 1283, 1238, 1202, 1182, 1144, 1099, 1072, 1053, 1029, 1005, 999, 969, 858, 826, 787, 757, 725, 710, 697, 658, 632, 560, 559, 513, 488, 445; ${ }^{1} \mathrm{H}-\mathrm{NMR}$ (DMSO-d $), \delta: 9.78(\mathrm{~s}, 1 \mathrm{H}), 7.98(\mathrm{~d}, J=8.9 \mathrm{~Hz}, 1 \mathrm{H}), 7.69(\mathrm{~d}, J=2.1 \mathrm{~Hz}, 1 \mathrm{H}), 7.65-7.64(\mathrm{~m}, 2 \mathrm{H}), 7.62$, $(\mathrm{d}, J=15.8 \mathrm{~Hz}, 1 \mathrm{H}), 7.47-7.41(\mathrm{~m}, 4 \mathrm{H}), 7.11(\mathrm{~d}, J=15.8 \mathrm{~Hz}, 1 \mathrm{H}) ;{ }^{13} \mathrm{C}-\mathrm{NMR}$ (DMSO-d6), $\delta: 164.02,141.17$, $134.62,134.21,129.99,129.09,129.05,128.95,127.88,127.59,126.57,126.43,121.54$.

(2E)-N-(2,4-Dibromophenyl)-3-phenylprop-2-enamide (3). Yield 49\%; Mp $190.8^{\circ} \mathrm{C}$; IR ( $\left.\mathrm{cm}^{-1}\right): 3263,2980$, 2888, 1653, 1620, 1575, 1521, 1464, 1446, 1376, 1336, 1280, 1240, 1203, 1184, 1080, 1040, 1007, 967, 859, 825, 766, 755, 711, 688, 643, 619, 566, 546, 501, 472, 440; ${ }^{1 H} \mathrm{H}-\mathrm{NMR}$ (DMSO-d $), \delta: 9.68$ (s, 1H), 7.94 $(\mathrm{d}, J=2.1 \mathrm{~Hz}, 1 \mathrm{H}), 7.78(\mathrm{~d}, J=8.9 \mathrm{~Hz}, 1 \mathrm{H}), 7.65-7.60(\mathrm{~m}, 4 \mathrm{H}), 7.47-7.41(\mathrm{~m}, 3 \mathrm{H}), 7.06(\mathrm{~d}, J=15.8 \mathrm{~Hz}$, 1H); ${ }^{13}$ C-NMR (DMSO-d $)$, $\delta: ~ 163.93,141.13,135.88,134.61,134.55,130.98,129.99,129.05,127.88$, 127.73, 121.50, 117.97, 117.66.

(2E)-3-Phenyl-N-(2,4,5-trichlorophenyl)prop-2-enamide (4). Yield 52\%; Mp $183.6{ }^{\circ} \mathrm{C}$; IR $\left(\mathrm{cm}^{-1}\right)$ : 3265, 3107, 3061, 3011, 1656, 1629, 1600, 1568, 1511, 1456, 1446, 1364, 1281, 1248, 1202, 1181, 1129, 1074, $1031,962,942,880,855,798,756,729,706,688,675,631,579,564,499,465,448 ;{ }^{~}{ }^{H}$-NMR (DMSO- $\left.d_{6}\right)$, ঠ: $9.85(\mathrm{~s}, 1 \mathrm{H}), 8.33(\mathrm{~s}, 1 \mathrm{H}), 7.94(\mathrm{~s}, 1 \mathrm{H}), 7.66-7.65(\mathrm{~m}, 2 \mathrm{H}), 7.64(\mathrm{~d}, J=15.8 \mathrm{~Hz}, 1 \mathrm{H}), 7.48-7.42(\mathrm{~m}, 3 \mathrm{H})$, $7.16(\mathrm{~d}, J=15.8 \mathrm{~Hz}, 1 \mathrm{H})$; ${ }^{13} \mathrm{C}-\mathrm{NMR}$ (DMSO-d $), \delta: 164.23,141.68,135.18,134.52,130.55,130.12,129.84$, $129.05,127.95,126.89,125.31,124.45,121.29$.

(2E)-3-Phenyl-N-(3,4,5-trichlorophenyl)prop-2-enamide (5). Yield 75\%; Mp $247.9{ }^{\circ} \mathrm{C}$; IR $\left(\mathrm{cm}^{-1}\right)$ : 3157, 3080, 1655, 1613, 1583, 1513, 1433, 1378, 1337, 1281, 1245, 1196, 1188, 1148, 1011, 998, 967, 944, 880, 860, 815, 762, 711, 685, 617, 602, 575, 536, 483; ${ }^{1} \mathrm{H}-\mathrm{NMR}$ (DMSO-d6), $\delta: 10.62$ (s, 1H), 7.95 (s, 2H), 7.65-7.62 (m, 3H), 7.47-7.42 (m, 3H), $6.74(\mathrm{~d}, J=15.8 \mathrm{~Hz}, 1 \mathrm{H})$; ${ }^{13} \mathrm{C}-\mathrm{NMR}$ (DMSO-d $\left.\mathrm{d}_{6}\right), \delta: 164.16,141.63$, $139.28,134.31,132.91,130.20,129.08,127.96,123.40,121.14,119.19$.

(2E)-N-(4-Bromo-3-chlorophenyl)-3-phenylprop-2-enamide (6). Yield 61\%; Mp $151.1{ }^{\circ} \mathrm{C}$; IR ( $\left.\mathrm{cm}^{-1}\right)$ : 3282, 3097, 2980, 2888, 1663, 1627, 1579, 1521, 1470, 1449, 1376, 1338, 1288, 1253, 1229, 1180, 1113, 1071, 968,

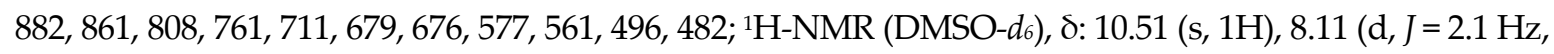
$1 \mathrm{H}), 7.72(\mathrm{~d}, J=8.2 \mathrm{~Hz}, 1 \mathrm{H}), 7.65-7.61(\mathrm{~m}, 3 \mathrm{H}), 7.50(\mathrm{dd}, J=8.6 \mathrm{~Hz}, 2.4 \mathrm{~Hz}, 1 \mathrm{H}), 7.47-7.41(\mathrm{~m}, 3 \mathrm{H}), 6.78$ $(\mathrm{d}, J=15.8 \mathrm{~Hz}, 1 \mathrm{H}) ;{ }^{13} \mathrm{C}-\mathrm{NMR}$ (DMSO- $\left.d_{6}\right), \delta: 163.94,141.13,139.92,134.47,133.95,133.09,130.07$, $129.08,127.88,121.53,120.31,119.45,114.48$.

(2E)-N-(2-Bromo-4-chlorophenyl)-3-phenylprop-2-enamide (7). Yield 68\%; Mp $184.1{ }^{\circ} \mathrm{C}$; IR ( $\left.\mathrm{cm}^{-1}\right)$ : 3258, 2980, 2888, 1653, 1621, 1572, 1524, 1465, 1447, 1380, 1336, 1279, 1263, 1238, 1201, 1180, 1093, 1039, 1006, 999, 969, 858, 824, 775, 757, 714, 700, 653, 632, 568, 551, 512; ${ }^{1} \mathrm{H}-\mathrm{NMR}$ (DMSO-d 6 ), $\delta: 9.69(\mathrm{~s}, 1 \mathrm{H}$ ), 7.84-7.82 (m, 2H), 7.65-7.64 (m, 2H), $7.62(\mathrm{~d}, J=15.8 \mathrm{~Hz}, 1 \mathrm{H}), 7.49(\mathrm{dd}, J=8.6 \mathrm{~Hz}, 2.4 \mathrm{~Hz}, 1 \mathrm{H})$, 7.47-7.41 (m, 3H), $7.07(\mathrm{~d}, J=15.8 \mathrm{~Hz}, 1 \mathrm{H})$; ${ }^{13} \mathrm{C}-\mathrm{NMR}$ (DMSO- $\mathrm{d}_{6}$ ), $\delta: 163.94,141.08,135.50,134.60$, $131.87,129.96,129.72,129.02,128.05,127.85,127.38,121.49,117.69$. 


\subsection{Lipophilicity Determination by HPLC (Capacity Factor k/Calculated Log $k$ )}

The HPLC separation system Merck Hitachi LaChrom Elite ${ }^{\circledR}$ equipped with a Merck Hitachi LaChrom Elite ${ }^{\circledR}$ L-2455 Diode-Array Detector (Hitachi High Technologies America, San Jose, CA, USA) was used. A chromatographic column Symmetry ${ }^{\circledR}$ C18 $5 \mu \mathrm{m}, 4.6 \times 250 \mathrm{~mm}$, Part No. W21751W016 (Waters Corp., Milford, MA, USA) was used. The HPLC separation process was monitored by the EZ CHROM Elite ${ }^{\circledR}$ software (Hitachi High Technologies America). Isocratic elution by a mixture of $\mathrm{MeOH}$ p.a. (72\%) and $\mathrm{H}_{2} \mathrm{O}-\mathrm{HPLC}$ Mili-Q grade (28\%) as a mobile phase was used. The total flow of the column was $1.0 \mathrm{~mL} / \mathrm{min}$, injection $20 \mu \mathrm{L}$, column temperature $40^{\circ} \mathrm{C}$ and sample temperature $10{ }^{\circ} \mathrm{C}$. The detection wavelength $210 \mathrm{~nm}$ was chosen. A KI methanolic solution was used for the dead time $\left(t_{D}\right)$ determination. Retention times $\left(t_{R}\right)$ were measured in minutes. The capacity factors $k$ were calculated according to the formula $k=\left(t_{R}-t_{D}\right) / t_{D}$, where $t_{R}$ is the retention time of the solute and $t_{D}$ is the dead time obtained using an unretained analyte. Each experiment was repeated three times. $\log k$, calculated from the capacity factor $k$, is used as the lipophilicity index converted to $\log P$ scale [4]. The $\log k$ values of individual compounds are shown in Table 1.

\subsection{Lipophilicity Calculations}

$\log P$, i.e., the logarithm of the partition coefficient for $n$-octanol/water, was calculated using the programs $\mathrm{ACD} / \mathrm{Chem}$ Sketch and $\mathrm{ACD} /$ Percepta (Advanced Chemistry Development. Inc., Toronto, ON, Canada, 2012) as well as ChemBioDraw Ultra 13.0 (CambridgeSoft, PerkinElmer Inc., Waltham, MA, USA). Clog $P$ values (the logarithm of $n$-octanol/water partition coefficient based on established chemical interactions) were calculated using ChemBioDraw Ultra 13.0 (CambridgeSoft) software. The results are shown in Table 1 . The distributive parameters $\pi \mathrm{Ar}$ of individual substituted anilide rings of individual compounds were predicted using ACD/Percepta and are shown in Table 2.

Acknowledgments: This study was supported by the Slovak Research and Development Agency (APVV-17-0373 and APVV-17-0318), by the Slovak Grant Agency for Science (VEGA 1/0787/18), and by the Ministry of Education of the Czech Republic (LO1305). Knowledge gained within project ITMS 26240120034 of the Center of Excellence in Security Research (CEBV) has been used in the results.

\section{References}

1. Lipinski, C.A.; Lombardo, F.; Dominy, B.W.; Feeney, P.J. Experimental and computational approaches to estimate solubility and permeability in drug discovery and development settings. Adv. Drug Deliv. Rev. 2001, 46, 3-26.

2. Lipinski, C.A. Lead- and drug-like compounds: the rule-of-five revolution. Drug Discov. Today Technol. 2004, 1, 337-341.

3. Kerns, E.H.; Di, L. Drug-Like Properties: Concepts. Structure Design and Methods: From ADME to Toxicity Optimization; Academic Press: San Diego, CA, USA, 2008.

4. Pliska. V. Lipophilicity in Drug Action and Toxicology, 1st ed.; (Methods and Principles in Medicinal Chemistry, Volume 4); Pliska, V., Testa. B., van der Waterbeemd, H., Eds.; Wiley-VCH: Weinheim, Germany, 1996; pp. 1-6.

5. Kucerova-Chlupacova, M.; Opletalova, V.; Jampilek, J.; Dolezel, J.; Dohnal, J.; Pour, M.; Kunes, J.; Vorisek, V. New hydrophobicity constants of substituents in pyrazine rings derived from RP-HPLC study. Coll. Czechoslov. Chem. Commun. 2008, 73, 1-18.

6. Musilek, K.; Jampilek, J.; Dohnal, J.; Jun, D.; Gunn-Moore, F.; Dolezal, M.; Kuca, K. RP-HPLC determination of the lipophilicity of bispyridinium reactivators of acetylcholinesterase bearing a but-2-ene connecting linker. Anal. Bioanal. Chem. 2008, 391, 367-372.

7. Musiol, R.; Jampilek, J.; Podeszwa, B.; Finster, J.; Tabak, D.; Dohnal, J.; Polanski, J. RP-HPLC determination of drug lipophilicity in series of quinoline derivatives. Cent. Eur. J. Chem. 2009, 7, 586-597.

8. Tengler, J.; Kapustikova, I.; Stropnicky, O.; Mokry, P.; Oravec, M.; Csollei, J.; Jampilek, J. Synthesis of new (arylcarbonyloxy)aminopropanol derivatives and the determination of their physico-chemical properties. Cent. Eur. J. Chem. 2013, 11, 1757-1767.

9. Kapustikova, I.; Bak, A.; Gonec, T.; Kos, J.; Kozik, V.; Jampilek, J. Investigation of hydro-lipophilic properties of $N$-alkoxyphenylhydroxynaphthalenecarboxamides. Molecules 2018, 23, 1635. 
10. Pospisilova, S.; Kos, J.; Michnova, H.; Kapustikova, I.; Strharsky, T.; Oravec, M.; Moricz, A.M.; Bakonyi, J.; Kauerova, T.; Kollar, P.; et al. Synthesis and spectrum of biological activities of novel N-arylcinnamamides. Int. J. Mol. Sci. 2018, 19, 2318.

11. Pospisilova, S.; Kos, J.; Michnova, H.; Strharsky, T.; Cizek, A.; Jampilek, J. N-Arylcinnamamides as Antistaphylococcal Agents. ECMC-4, 1-30 November 2018; p. 5576. Available online: https://sciforum.net/ manuscripts/5576/slides.pdf (accessed on 30 November 2018).

12. Gonec, T.; Kos, J.; Zadrazilova, I.; Pesko, M.; Keltosova, S.; Tengler, J.; Bobal, P.; Kollar, P.; Cizek, A.; Kralova, K.; et al. Antimycobacterial and herbicidal activity of ring-substituted 1-hydroxynaphthalene2-carboxanilides. Bioorg. Med. Chem. 2013, 21, 6531-6541.

13. Gonec, T.; Pospisilova, S.; Kauerova, T.; Kos, J.; Dohanosova, J.; Oravec, M.; Kollar, P.; Coffey, A.; Liptaj, T.; Cizek, A.; et al. N-Alkoxyphenylhydroxynaphthalene-carboxamides and their antimycobacterial activity. Molecules 2016, 21, 1068.

14. Gonec, T.; Kralova, K.; Pesko, M.; Jampilek, J. Antimycobacterial N-alkoxyphenyl- hydroxynaphthaleneca rboxamides affecting photosystem II. Bioorg. Med. Chem. Lett. 2017, 27, 1881-1885.

15. Gonec, T.; Kos, J.; Pesko, M.; Dohanosova, J.; Oravec, M.; Liptaj, T.; Kralova, K.; Jampilek, J. Halogenated 1-hydroxynaphthalene-2-carboxanilides affecting photosynthetic electron transport in photosystem II. Molecules 2017, 22, 1709.

16. Michnova, H.; Pospisilova, S.; Gonec, T.; Kapustikova, I.; Kollar, P.; Kozik, V.; Musiol, R.; Jendrzejewska, I.; Vanco, J.; Travnicek, Z.; et al. Bioactivity of methoxylated and methylated 1-hydroxynaphthalene-2carboxanilides: comparative molecular surface analysis. Molecules 2019, 24, 2991.

17. Spaczynska, E.; Mrozek-Wilczkiewicz, A.; Malarz, K.; Kos, J.; Gonec, T.; Oravec, M.; Gawecki, R.; Bak, A.; Dohanosova, J.; Kapustikova, I.; et al. Design and synthesis of anticancer 1-hydroxynaphthalene-2carboxanilides with a p53 independent mechanism of action. Sci. Rep. 2019, 9, 6387.

18. Kos, J.; Zadrazilova, I.; Pesko, M.; Keltosova, S.; Tengler, J.; Gonec, T.; Bobal, P.; Kauerova, T.; Oravec, M.; Kollar, P.; et al. Antibacterial and herbicidal activity of ring-substituted 3-hydroxynaphthalene-2carboxanilides. Molecules 2013, 18, 7977-7997.

19. Gonec, T.; Kos, J.; Nevin, E.; Govender, R.; Pesko, M.; Tengler, J.; Kushkevych, I.; Stastna, V.; Oravec, M.; Kollar, P.; et al. Preparation and biological properties of ring-substituted naphthalene-1-carboxanilides. Molecules 2014, 19, 10386-10409.

20. Kos, J.; Zadrazilova, I.; Nevin, E.; Soral, M.; Gonec, T.; Kollar, P.; Oravec, M.; Coffey, A.; O’Mahony, J.; Liptaj, T.; et al. Ring-substituted 8-hydroxyquinoline-2-carboxanilides as potential antimycobacterial agents. Bioorg. Med. Chem. 2015, 23, 4188-4196.

21. Hansch, C.; Leo, A.; Unger, S.H.; Kim, K.H.; Nikaitani, D.; Lien, E.J. "Aromatic" substituent constants for structure-activity correlations. J. Med. Chem. 1973, 16, 1207-1216.

22. Norrington, F.E.; Hyde, R.M.; Williams, S.G.; Wootton, R. Physicochemical-activity relations in practice I. A rational and self-consistent data bank. J. Med. Chem. 1975, 18, 604-607.

23. Dearden, J.C. Partitioning and lipophilicity in quantitative structure-activity relationships. Environ. Health Perspect. 1985, 61, 203-228.

24. Zhang, M.; Lu, X.; Zhang, H.J.; Li, N.; Xiao, Y.; Zhu, H.L.; Ye, Y.H. Synthesis, structure, and biological assay of cinnamic amides as potential EGFR kinase inhibitors. Med. Chem. Res. 2013, 22, 986-994.

(C) 2020 by the authors. Licensee MDPI, Basel, Switzerland. This article is an open access article distributed under the terms and conditions of the Creative Commons Attribution (CC BY) license (http://creativecommons.org/licenses/by/4.0/). 